\title{
Osteogenic Potential and Histological Characteristics of Mesenchymal Stem Cell Sheet/Hydroxyapatite Constructs
}

\author{
Hideki Shigematsu ${ }^{*}, 1$, Manabu Akahane ${ }^{2}$, Yoshiko Dohi ${ }^{2}$, Akifumi Nakamura ${ }^{1}$, Hajime Ohgushi ${ }^{3}$, \\ Tomoaki Imamura ${ }^{2}$ and Yasuhito Tanaka ${ }^{1}$ \\ ${ }^{I}$ Department of Orthopedic Surgery, Nara Medical University School of Medicine, Kashihara, Nara 634-8522, Japan \\ ${ }^{2}$ Department of Public Health, Health Management and Policy, Nara Medical University School of Medicine, \\ Kashihara, Nara 634-8521, Japan \\ ${ }^{3}$ Research Institute for Cell Engineering, National Institute of Advanced Industrial Science and Technology, Amagasaki, \\ Hyogo 661-0974, Japan
}

\begin{abstract}
We have developed a new cell transplantation technique, in which mesenchymal stem cells (MSCs) were cultured and lifted as a cell sheet structure. The sheet formed bone tissue after in vivo transplantation at a subcutaneous site, without the need for any scaffold. The sheet could also be transplanted with a scaffold, such as hydroxyapatite (HA). Transplantation of this sheet/HA construct resulted in extensive bone formation. The purpose of the present study was to analyze the spatial distribution and biological potential of the osteogenic sheet/HA constructs. Histological examination showed that the construct allowed bone formation inside the pores, as well as outside the HA at 2 weeks after transplantation. Interestingly, when two HAs were wrapped in one sheet, the bone on the outside of one HA could bond to the bone on the other HA, resulting in union of two HAs. Biochemical investigation showed that the sheet/HA constructs had higher osteogenic potential than previous methods, such as MSC/HA constructs. Our results indicate that this transplantation technique using MSC sheets has the potential to be a useful tool in bone tissue engineering.
\end{abstract}

Keywords: Bone marrow, mesenchymal stem cells, hydroxyapatite, osteogenesis, cell sheet.

\section{INTRODUCTION}

Many orthopedic surgeons have experienced clinical cases of bone defects resulting from trauma, infection and resection of bone tumors, etc. Surgery for skeletal reconstruction is required in these cases. The most frequently used method for reconstruction is an autogenous bone graft from the ilium and tibia, because it supplies a structural scaffold as well as osteoinductive growth factors and osteogenic cells. This seems to be ideal for skeletal reconstruction, because of the low potential for disease transmission and immunological rejection. However, surgeons sometimes encounter complications of pain and nerve palsy after bone harvesting, due to damage to healthy bone and soft tissue. The size of harvested autogenous bone is also limited. Allografts or xenografts can be used instead of autografts to reduce the complications of harvested autogenous bone. However, these alternatives carry risks of immunological rejection, bacterial contamination and disease transmission. Hence, biomaterials such as hydroxyapatite (HA) and tricalcium phosphate have been used in clinical cases, rather than allografts [1]. However, although these materials show good osteoconductive potential, they do not usually have osteoinductive potential.

*Address correspondence to this author at the Department of Orthopedic Surgery, Nara Medical University School of Medicine, Nara, Japan. E-mail: shideki@naramed-u.ac.jp
It is well known that bone marrow consists of stem cells called mesenchymal stem cells (MSCs) and stromal stem cells [2-4]. MSCs can differentiate into osteoblasts, chondrocytes, adipocytes, and muscle cells, and can also differentiate into osteoblastic cells after culturing in osteoinductive medium containing dexamethasone (Dex), ascorbic acid phosphate (vitamin $\mathrm{C}$ phosphate), and $\beta$-glycerophosphate $(\beta-\mathrm{GP})[5-7]$. We previously reported that a construct of porous biomaterial and cultured MSCs showed osteogenic potential $[3,8,9]$. The potential of the constructs was demonstrated by biochemical analyses of factors such as osteocalcin (OC) content and alkaline phosphatase (ALP) activity, as well as by the levels of gene expression of various bone matrix proteins [10].

We have recently developed a new cell transplantation technique for MSCs that eliminates the need for scaffolds. MSCs were cultured in the presence of Dex and ascorbic acid phosphate and lifted as a cell sheet structure, with no special materials, such as thermosensitive polymers [11]. The harvested cell sheet could be transplanted without a scaffold, resulting in bone formation at a subcutaneous site. We also developed a construct comprising a cell sheet and HA (sheet/HA construct). However, the osteogenic potential of the sheet/HA construct has not been compared with that of the previously reported MSC/HA construct. Thus the present study aimed to compare the osteogenic potential of sheet/HA and MSC/HA constructs. 


\section{MATERIALS AND METHODS}

\section{Preparation of Bone Marrow Mesenchymal Stem Cells and Cell Culture}

Approval from the animal experimental review board of Nara Medical University was obtained before the start of the experiments. Seven-week-old male Fischer 344 rats were used as donors and recipients. The method of bone marrow cell preparation has been reported previously $[6,12]$. Briefly, fresh bone marrow cells were obtained from both femoral shafts of donor rats by flushing out with culture medium expelled gently from a syringe equipped with a 21-gauge needle. The released cells were seeded in two T-75 flasks (75- $\mathrm{cm}^{2}$ culture flask, Costar Co., Cambridge, MA, USA) containing $15 \mathrm{~mL}$ of standard medium, comprising Earle's minimal essential medium (MEM; Nacalai Tesque. Kyoto, Japan) supplemented with $15 \%$ fetal bovine serum (FBS, JRH Biosciences, Lenexa, KS, USA) and a mixture of antibiotics $(100 \mathrm{U} / \mathrm{mL}$ penicillin and $100 \mu \mathrm{g} / \mathrm{mL}$ streptomycin, Nacalai Tesque). The cells were cultured in a humidified atmosphere of $95 \%$ air and $5 \% \mathrm{CO}_{2}$ at $37^{\circ} \mathrm{C}$. The medium was subsequently renewed three times a week. After 10 days of primary culture, the adherent MSCs were released with $0.25 \%$ trypsin/EDTA solution (Gibco, Invitrogen, CA, USA).

\section{Preparation of Constructs of HA Ceramics Containing MSCs}

We have previously reported the preparation methods for MSC/HA constructs, cultured MSC/HA constructs, and cell sheet/HA constructs $[11,13]$. Briefly, after release from the substratum, MSCs were concentrated by centrifugation and resuspended at a density of $1 \times 10^{7}$ cells $/ \mathrm{mL}$ in standard medium. The porous HA disks (CELLYARD HA scaffolds, $50 \%$ average void volume, 5-mm diameter, and 2-mm thickness, Pentax Co, Tokyo, Japan) were soaked in the cell suspension for 2 hours in a $\mathrm{CO}_{2}$ incubator at $37^{\circ} \mathrm{C}$ to produce the MSC/HA construct. The MSC/HA construct was transplanted subcutaneously into rats.

An HA disk was soaked in a cell suspension of $1 \times 10^{7}$ cells/mL, and the construct was then transferred into a 24well plate (Falcon, Franklin Lakes, NJ) in $1 \mathrm{~mL}$ of osteoinductive medium consisting of standard medium, $82 \mu \mathrm{g} / \mathrm{mL}$ ascorbic acid phosphate (Wako Pure Chemical Industrials, Kyoto, Japan) and $10 \mathrm{nM}$ Dex (Sigma, St. Louis, MO, USA) for further subculture. After 10 days of subculture, $10 \mathrm{mM} \beta$ GP was added into the conditioning culture medium 12 hours before transplantation. The cultured MSC/HA construct was then transplanted into rats.

To prepare cell sheets, released cells were seeded at a density of $1 \times 10^{4}$ cells $/ \mathrm{cm}^{2}$ into a $35-\mathrm{mm}$ culture dish (Falcon) for subculture with $10 \mathrm{nM}$ Dex and $82 \mu \mathrm{g} / \mathrm{mL}$ ascorbic acid phosphate. Cells were subcultured until confluence (about 10 days), then $10 \mathrm{mM} \beta-\mathrm{GP}$ was added to the conditioning culture medium 12 hours before transplantation. The cells were then rinsed twice with phosphate-buffered saline (PBS; Gibco) and lifted as a cell sheet using a scraper $[11,14]$. An HA disk was wrapped in the cell sheet to produce the sheet/HA construct. We prepared three experimental groups to compare the different constructs: group 1, MSC/HA construct; group 2, cultured MSC/HA construct; group 3, sheet/HA construct, as illustrated in Fig. (1).

\section{Primary culture for 10 days}

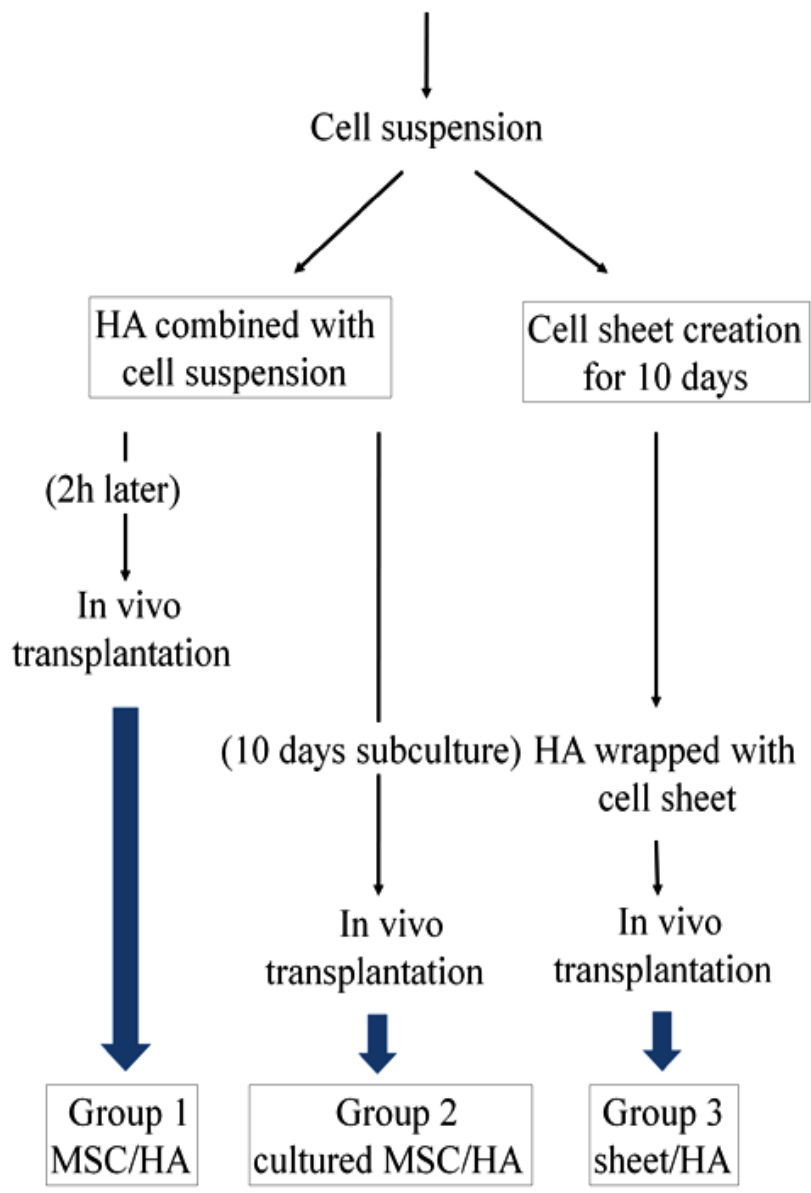

Fig. (1). Summary of the experimental method.

\section{Transplantation of the Constructs}

Constructs from each group were transplanted at six sites on the backs of syngeneic rats, as previously reported $[15,16]$. They were harvested at 2,4 and 8 weeks after transplantation. Three and six constructs from each group, harvested at 2, 4 and 8 weeks, were used for histological sections and biochemical analyses, respectively. Another six constructs from each group were harvested at 2 weeks and used for gene expression analysis. These analyses were repeated twice.

We performed an additional experiment to evaluate whether the cell sheet could unite two disks of HA by bridging bone formation. Briefly, two disks of HA were fixed with a needle and subsequently wrapped in a cell sheet created in a $10-\mathrm{cm}$ culture dish (sheet/2HA construct). Fig. $(\mathbf{2 A}, \mathbf{B})$ shows the appearance of the sheet/2HA construct just before implantation. The construct was transplanted subcutaneously into the backs of syngeneic rats and harvested at 8 weeks after transplantation. 

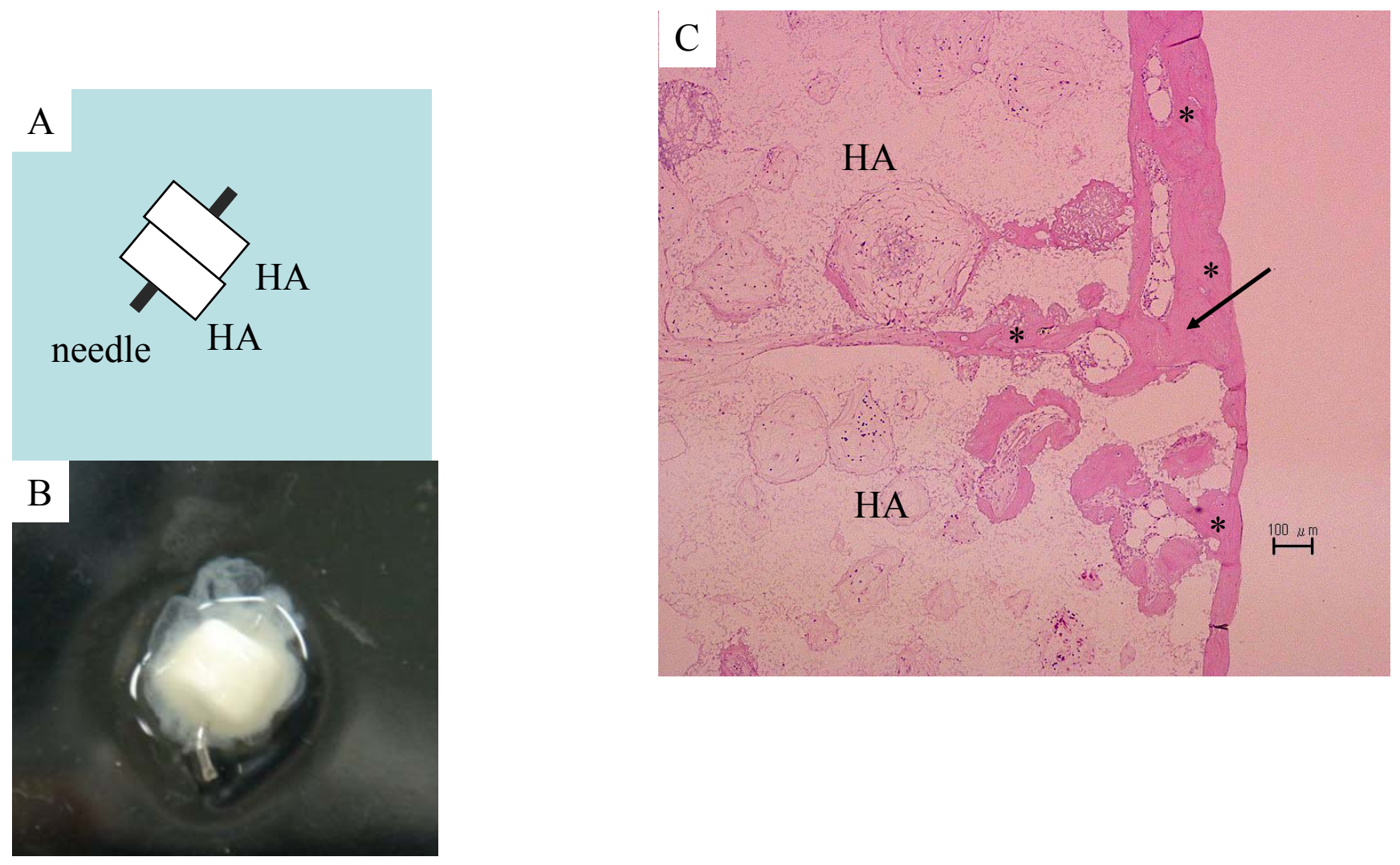

Fig. (2). Experimental model of cell sheet/2HA construct. A) Illustration of cell sheet/2HA construct. (B) Appearance of cell sheet/2HA construct. (C) De novo bone was observed in the pore, as well as on the surface of the combined HAs. Two HA ceramics were connected by the newly formed bridging bone. Asterisks and arrow indicate bone area and connective sites, respectively. Bar indicates $100 \mu \mathrm{m}$.

\section{Histological Examination}

The transplanted constructs in each group were fixed with $10 \%$ buffered formalin, decalcified with K-CX solution (Falma Co., Tokyo, Japan) for 2 days and embedded in paraffin. The middle of each specimen was cut into $8-\mu \mathrm{m}$ sections, parallel to the round surface of the HA disk, and the sections were stained with hematoxylin and eosin.

\section{Gene Expression Analysis}

Gene expression levels of ALP and OC were measured by real-time quantitative polymerase chain reaction (RTPCR) in the constructs in each group, harvested at 2 weeks after transplantation. Total RNA was isolated from each construct using an ISOGEN RNA Extraction Kit (Nippon Gene Co. Ltd., Tokyo, Japan). Briefly, each construct in ISOGEN solution was disrupted with matrix beads using a FastPrep FP120 Cell Disrupter (Qbiogene, Inc., Carlsbad, CA, USA) and RNA isolation was subsequently performed according to the manufacturer's instructions. Two micrograms of total RNA were converted into cDNA using a High Capacity cDNA Archive Kit (Applied Biosystems, Foster City, CA, USA). The cDNA was used for subsequent realtime PCR, using specific primers and fluorogenic probes, as described previously [17]. Known amounts of rat cDNA fragments of ALP, OC and glyceraldehyde-3-phosphate dehydrogenase (GAPDH) were used as standards, as in previous reports $[17,18]$.
The thermal cycle conditions were: 10 minutes at $95^{\circ} \mathrm{C}$ for activation of the AmpliTaq Gold DNA polymerase, followed by 40 cycles of 15 seconds at $95^{\circ} \mathrm{C}$ for denaturing and 1 minute at $60{ }^{\circ} \mathrm{C}$ for annealing and extension. The levels of target mRNA (ALP and OC mRNA) were compared after normalizing against the GAPDH mRNA level as internal standard, to adjust for differences in the efficiency of reverse transcription among samples.

\section{Biochemical Analysis}

ALP activity and OC contents were measured as previously reported [13]. Briefly, each construct was crushed and homogenized in $1 \mathrm{~mL}$ of $0.2 \%$ Nonidet P-40 (NP-40) at $4^{\circ} \mathrm{C}$ using a microhomogenizer, and centrifuged at 13,000 rpm for 10 minutes at $4{ }^{\circ} \mathrm{C}$. An aliquot of the supernatant was added to ALP substrate buffer containing $56 \mathrm{mM}$ 2-amino-2methylpropanediol (AMP) buffer, $\mathrm{pH}$ 9.8, $10 \mathrm{mM} p$ nitrophenyl phosphate, and $1 \mathrm{mM} \mathrm{MgCl}_{2}$, and incubated for 30 minutes at $37^{\circ} \mathrm{C}$. The reaction was stopped by adding 2 $\mathrm{mL}$ of $0.2 \mathrm{~N} \mathrm{NaOH}$. Absorption was measured at $410 \mathrm{~nm}$ using a spectrophotometer. ALP activity was represented as $\mu \mathrm{mol}$ of $p$-nitrophenol per construct released during 30 minutes incubation at $37^{\circ} \mathrm{C}$.

OC was extracted from the sediments following extraction with $0.2 \% \mathrm{NP}-40$ in $4 \mathrm{~mL}$ of $20 \%$ formic acid for 2 weeks at $4^{\circ} \mathrm{C}$. An aliquot $(0.5 \mathrm{~mL})$ of the formic acid extract was then applied to a prepacked Sephadex G-25 column (NAP-5 column; Amersham Pharmacia Biotech AB, 
Uppsala, Sweden), and eluted with $10 \%$ formic acid. Protein fractions were pooled and lyophilized. After dissolution in $0.5 \mathrm{~mL}$ ELISA sample buffer, the amount of deposited OC was assayed using the OC ELISA system (Rat Osteocalcin ELISA Kit DS; DS Pharma Biomedical Co., Ltd. Osaka, Japan) [19].

\section{Statistical Analysis}

Variances and means among the three groups were compared by one-way ANOVA. Post-hoc multiple comparisons were made using Tukey's test. Statistical significance was considered for $p<0.05$.

\section{RESULTS}

\section{Histological Findings}

Bone tissue was observed together with many active osteoblasts in the HA pores in all groups at 2, 4 and 8 weeks after transplantation. Newly formed bone increased in all groups with length of time since transplantation. Interestingly, the sheet/HA construct (group 3) showed unique findings; abundant bone formation was observed not only inside the pore, but also on the outer HA surface (Fig. 3 $\mathbf{C , c}, \mathbf{F}, \mathbf{f}, \mathbf{I}, \mathbf{i})$. Bone formation on the outer HA surface was never observed in the other groups (Fig. 3 A,a,B,b,D,d,
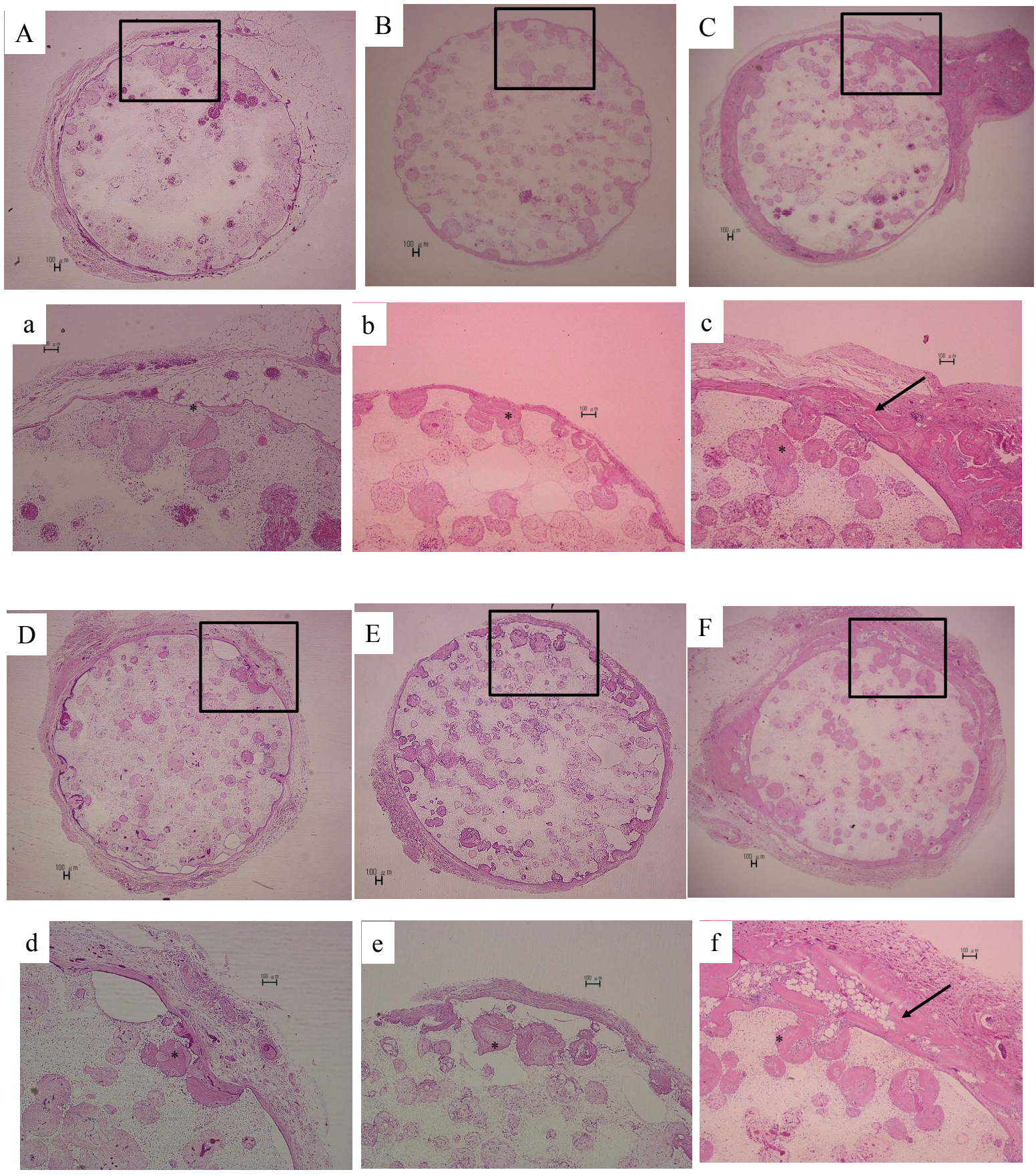

(Fig. 3) Contd..... 

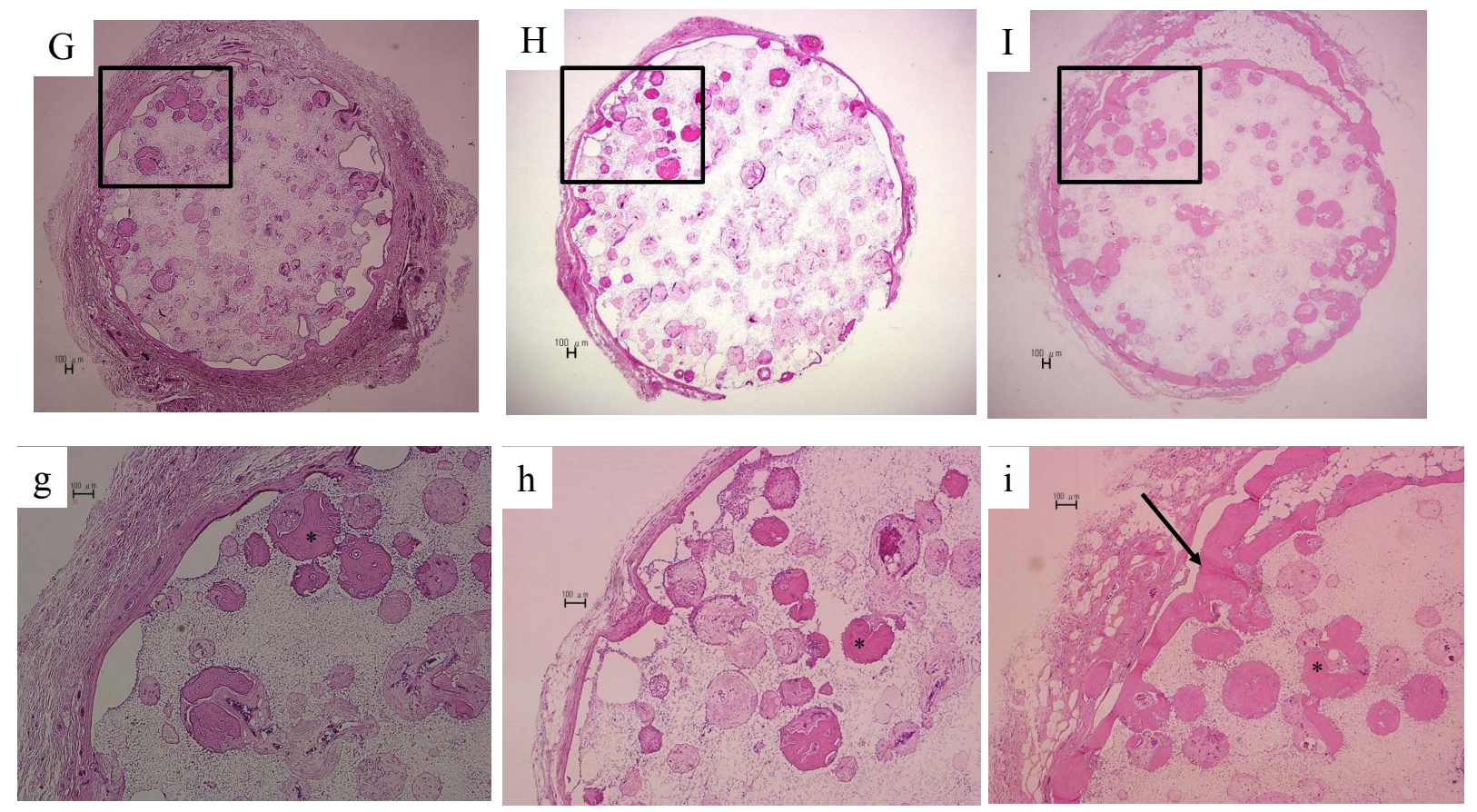

Fig. (3). Histological findings of harvested constructs. The constructs were harvested at 2 (A, B, C), 4 (D, E, F) and 8 (H, I, J) weeks after implantation. Bone tissue was observed only inside the HA pores in the MSC/HA construct (A, D, $\mathbf{H})$ and the cultured MSC/HA construct (B, E, I). In contrast, mature bone tissue, together with active osteoblasts, were observed both inside the pores and on the outside of the HA in the sheet/HA construct $(\mathbf{C}, \mathbf{F}, \mathbf{J})$. The figures labeled (a) to (j) show higher magnification images of the rectangular areas in figures (A) to $(\mathbf{J})$. Asterisk indicates bone area in the pore of HA. Arrow indicates bone on the surface of the HA. Bar indicates $100 \mu \mathrm{m}$.

$\mathbf{E}, \mathbf{e}, \mathbf{G}, \mathbf{g}, \mathbf{H}, \mathbf{h})$. Bone tissues formed in both the pores and on the surface of the HA were mature bone with active osteoblasts and osteocytes. However, the bone formation pattern differed among groups 1, 2 and 3. Groups 1 and 2, which received cell suspensions, showed steady bone formation in the pores of the HA during the initial 2 weeks. In contrast, the bone tissue in group 3 (sheet/HA) was abundant on the surface, rather than in the central pores of the HA.

\section{ALP mRNA}

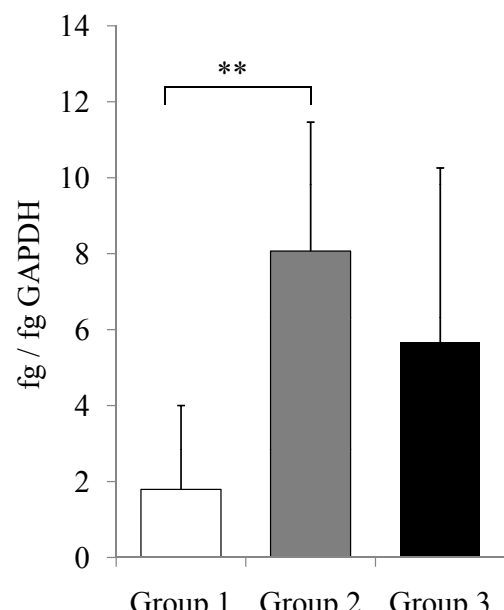

The histological findings of the sheet/2HA construct were also interesting. Bridging bone was formed resulting in bony union of the two HAs (Fig. 2C).

\section{Gene Expression of ALP and OC}

ALP and OC mRNA expression were observed in the cell/HA constructs in all groups 2 weeks after transplantation. Group 2 showed significantly higher expression of both ALP and OC mRNA compared with group 1 (Figs. 4 A, OC mRNA

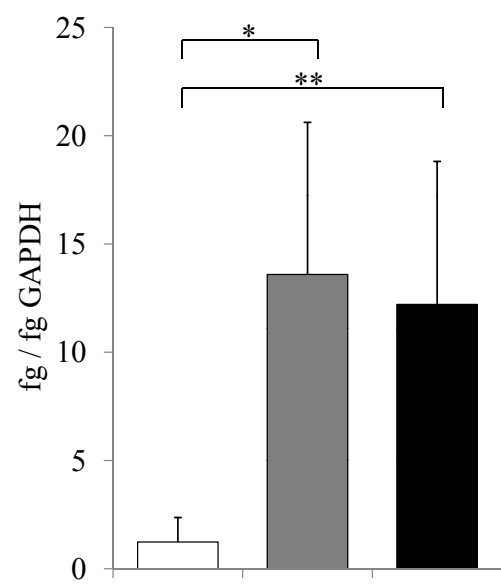

Group 1 Group 2 Group 3

Fig. (4). Expression of alkaline phosphatase (A) and osteocalcin (B) mRNA in Groups 1, 2 and 3 harvested at 2 weeks after transplantation. Group 1: construct of MSC/HA (open bars), Group 2: construct of cultured MSC/HA (gray bars), Group 3: construct of sheet/HA (black bars). Data represent means $\pm \mathrm{SD}(n=6)$. *indicates $p<0.01$. **indicates $p<0.05$. 

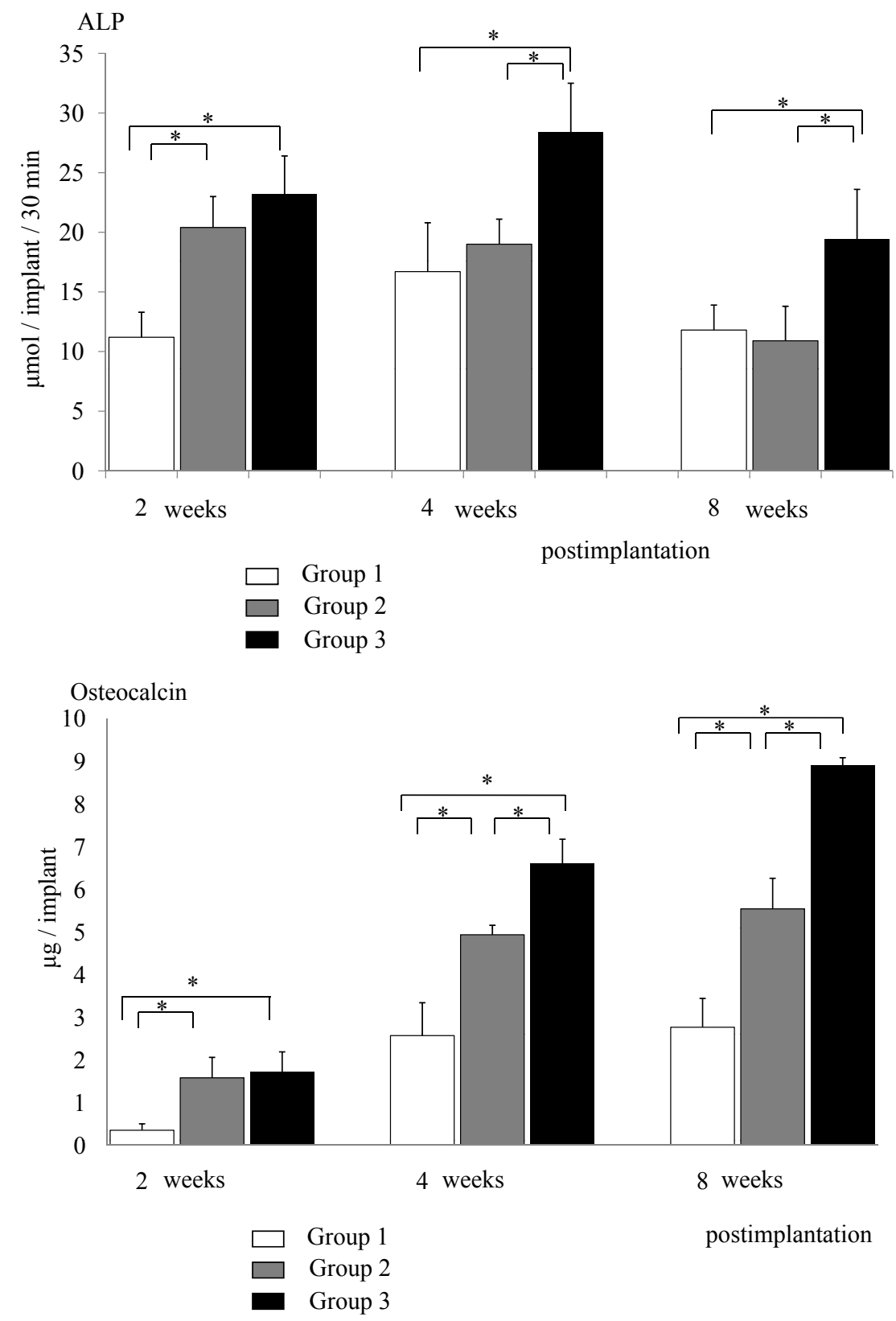

Fig. (5). Alkaline phosphatase activity (A) and osteocalcin contents (B) in Groups 1, 2 and 3 harvested at 2, 4 and 8 weeks after transplantation. Group 1: construct of MSC/HA (open bars), Group 2: construct of cultured MSC/HA (gray bars), Group 3: construct of sheet/HA (black bars). Data represent means $\pm \mathrm{SD}(n=6)$. *indicates $p<0.01$.

B). OC mRNA expression in group 3 was significantly higher than that of group 1.

\section{Biochemical Analyses}

The ALP activities of the MSC/HA construct and the sheet/HA construct peaked at 4 weeks after transplantation. In contrast, the activity in the cultured MSC/HA construct tended to peak at 2 weeks, and then decrease gradually. The activities in the cultured MSC/HA construct (group 2) and sheet/HA construct (group 3) were approximately two-fold higher than that in the MSC/HA construct (group 1) 2 weeks after transplantation. The ALP activity in group 3 was the highest among the groups during the experimental period (Fig. 5A).
OC was detectable in all groups, even at 2 weeks after transplantation, and was followed by a steady increase over the experimental period. The OC content in the constructs in Group 3 was also higher than in the other groups at all time points, reflecting the pattern of ALP activity (Fig. 5B).

\section{DISCUSSION}

We performed histological, biochemical and gene expression analyses to compare the osteogenic potential of three types of constructs. Our results showed that the cell sheet/HA construct had the highest osteogenic potential among the three groups and produced characteristic histological patterns of newly formed bone. 
We have described several methods for making artificial bone using HA with osteogenic ability by combining marrow cells and culture-expanded MSCs [16,20,21]. The first method combined HA with freshly prepared bone marrow cells. This construct showed osteogenic potential and was designated as the fresh marrow cell/HA construct. However, significant amounts of fresh marrow cells were required to obtain stable bone formation after in vivo transplantation. We subsequently then developed a combination of HA with cultured MSCs. MSCs can be expanded using proper culture techniques, thus generating enough cells to combine with HA. We therefore combined cultured MSCs $\left(1 \times 10^{7}\right.$ cells $/ \mathrm{mL}$ suspension) with HA. This construct has steady osteogenic potential and was designated as the MSC/HA construct (Group 1). Third, we modified the fabrication method of the MSC/HA construct. We made a construct of $\mathrm{MSC} / \mathrm{HA}$ using a suspension of $1 \times 10^{7} \mathrm{MSC}$ cells $/ \mathrm{mL}$, and then further subcultured the construct. The subcultured construct was designated as the cultured MSC/HA construct (Group 2). The MSC/HA construct was transplanted into rats immediately after the combination of HA with MSCs, while the cultured MSC/HA construct was transplanted after an additional 2 weeks culture in the osteoinductive medium.

The advantages of the cultured MSC/HA construct were as follows: 1) reduction in the number of cells required to make the HA/cell construct; and 2) earlier and greater bone formation compared with the fresh marrow/HA construct. However, using the HA construct combined with cell suspension (including fresh marrow or cultured MSCs), bone formed only in the pores of the HA. In contrast, the sheet/HA construct (Group 3) produced de novo bone not only inside, but also on the surface of the HA. MSC suspensions were used to make the constructs of cultured MSCs/HA and MSC/HA, allowing the MSCs to easily enter the central pore of the HA, so resulting in steady bone formation in the pore. In contrast, the cell sheet simply attached to the HA surface, and there were therefore no MSCs in the central pore during the initial phase. However, some MSCs were able to migrate from the sheet into the pores to allow the development of some new bone tissue in the pores. Thus the bone tissue in the MSC sheet/HA constructs was more abundant on the surface, rather than in the central pore of the HA.

Interestingly the surface bone was able to unite two HA disks. When MSC/HA or cultured MSC/HA constructs were implanted in bony defects, non-union between the HA and host bone was sometimes seen. The bridging bone formed when using the sheet/HA construct may therefore have the potential to unite the implanted HA and the host bone in clinical situations, such as during bone reconstruction surgery with HA.

Kumar et al. reported a method for preparing cell sheet/ HA constructs using a thermosensitive polymer to fabricate the cell sheet [22]. They showed rapid and complete cellularization of HA by wrapping it in a cell sheet fabricated from a human osteosarcoma cell line. MSCs have already been used in many clinical situations, and we therefore used these cells to make the constructs in the present study. Gao et al. also reported the results of osteogenic cell sheet transplantation using rabbit MSCs [23]. They used osteogenic cell sheets for the regeneration of bone grafts. However, there was no bone formation on the outer HA surface in their model. In addition, our method only requires the use of regular cell culture equipment, while the methods of Kumar et al. and Gao et al. require special culture dishes coated with thermosensitive polymers. Our method is therefore both simpler and cheaper than these previous methods.

The cell sheet may be displaced by the pressure of the surrounding tissue, such as muscles, when the sheet is transplanted in vivo. In the present study, we observed newly formed bone in cases of sheet/HA construct transplantation. However, bone formation on the surface of the HA varied among the constructs. Because the HA was simply wrapped in the sheet, the uneven distribution of bone tissue around the HA was possibly due to detachment of the sheets after transplantation. However, this was not a serious problem, because abundant bone formation still occurred in all sheet/HA constructs. We suggest that the sheet/HA construct could have clinical applications in the treatment of osteonecrosis, such as femoral head necrosis, Kienbeck disease and bone defects. The sheet might be partially displaced after transplantation into the necrotic bone, but the displaced sheet could also form bone tissue within the necrotic bone. Moreover, when the construct is used for filling bone defects, bone formation on the surface of the HA would unite the HA to the recipient bone. These features suggest that this technique has potential clinical applications.

In conclusion, we quantitatively and qualitatively analyzed the osteogenic potential of a cell sheet/HA construct. Our results indicated that the sheet/HA construct had higher osteogenic potential than other previously reported constructs of MSC/HA and cultured MSC/HA; only the sheet/HA showed abundant bone tissue formation on the surface of the HA. As the fabrication of the sheet/HA construct needs no special equipment, it could provide a powerful tool for bone tissue engineering.

\section{REFERENCES}

[1] John A, Abiraman S, Varma H, Kumari T, Umasankar P. Bone growth response with porous hydroxyapatite granules in a critical sized lapine tibial-defect model. Bull Mater Sci 2002; 25: 141-54.

[2] Friedenstein AJ, Ivanov-Smolenski AA, Chajlakjan RK, et al. Origin of bone marrow stromal mechanocytes in radiochimeras and heterotopic transplants. Exp Hematol 1978; 6: 440-4.

[3] Ohgushi H, Caplan AI. Stem cell technology and bioceramics: from cell to gene engineering. J Biomed Mat Res 1999; 48; 913-27.

[4] Owen M. Marrow stromal stem cells. J Cell Sci 1988; 10: 63-76.

[5] Maniatopoulos C, Sodek J, Melcher AH. Bone formation in vitro by stromal cells obtained from marrow and young adult rats. Cell Tissue Res 1988; 254: 317-30.

[6] Ohgushi H, Dohi Y, Katuda T, Tmai S, Tabata S, Surwa Y. In vitro bone formation by rat marrow cell culture. J Biomed Mater Res 1996; 32: 333-40.

[7] Ter Brugge PJ, Jansen JA. In vitro osteogenic differentiation of rat bone marrow cells subcultured with and without dexamethasone. Tissue Eng 2002; 8: 321-31.

[8] Kotobuki N, Ioku K, Kawagoe D, Fujimori H, Goto S, Ohgushi S. Observation of osteogenic differentiation cascade of living mesenchymal stem cells on transparent hydroxyapatite ceramics. Biomater 2005; 26: 779-85.

[9] Takahashi Y, Yamamoto M, Tabata Y. Osteogenic differentiation of mesenchymal stem cells in biodegradable sponges composed of gelatin and beta-tricalcium phosphate. Biomaterials 2005; 26: 3587-96.

[10] Yao KL, Todescan R. Jr, Sodek J. Temporal changes in matrix protein synthesis and m-RNA expression during mineralized tissue 
formation by adult rat bone marrow cells in culture. J Bone Miner Res 1994; 9: 231-40.

[11] Akahane M, Nakamura A, Ohgushi H, Shigematsu H, Dohi Y, Takakura Y. Osteogenic matrix sheet - new cell transplantation technique of mesenchymal stem cells resulted in bone formation without scaffold at ectopic site. J Tissue Eng Regen Med 2008; 2: 196-201.

[12] Akahane M, Ohgushi H, Kuriyama S, Akahane T, Takakura Y. Hydroxyapatite ceramics as a carrier of gene-transduced bone marrow cells. J Orthop Sci 2002; 7: 677-82.

[13] Iida J, Yoshikawa T, Akahane M, et al. Osteogenic potential of cultured bone/ceramic construct: comparison with marrow mesenchymal cell/ceramic composite. Cell Transplant 2004; 13: $357-65$.

[14] Nakamura A, Akahane M, Shigematsu H, et al. Cell sheet transplantation of cultured mesenchymal stem cells enhances bone formation in a rat nonunion model. Bone [Epub ahead of prin].

[15] Noshi T, Yoshikawa T, Ikeuchi M, et al. Enhancement of the in vivo osteogenic potential of marrow/hydroxyapatite composites by bovine bone morphogenetic protein. J Biomed Mater Res 2000; 52: 621-30.

[16] Yoshikawa T, Ohgushi H, Tamai S. Immediate bone forming capability of prefabricated osteogenic hydroxyapatite. J Biomed Mater Res 1996; 32: 481-92.
[17]

Shimaoka H, Dohi Y, Ohgushi $\mathrm{H}$, et al. Recombinant growth/differentiation factor-5 (GDF-5) stimulates osteogenic differentiation of marrow mesenchymal stem cells in porous hydroxyapatite ceramic. J Biomed Mater Res A 2004; 68: 168-76.

[18] Tohma Y, Tanaka Y, Ohgushi H, et al. Early bone in-growth ability of alumina ceramic implants loaded with tissue-engineered bone. J Orthop Res 2006; 24: 595-603

[19] Nakamura A, Dohi Y, Akahane M, et al. Osteocalcin secretion as an early marker for in vitro osteogenic differentiation of rat mesenchymal stem cells. Tissue Eng Part C Methods 2009; 15: 169-80.

[20] Ohgushi H, Dohi Y, Tamai S, Tabata S. Osteogenic differentiation of marrow stromal stem cells in porous hydroxyapatite ceramics. J Biomed Mater Res 1993; 27; 1401-7.

[21] Yoshikawa T, Ohgushi H, Okumura M, Tamai S, Dohi Y, Moriyama T. Biochemical and histological sequences of membranous ossification in ectopic site. Calcif Tissue Int 1992; 50: 184-88.

[22] Anil Kumar P.R, Varma H.K, Kumary T.V. Rapid and complete cellularization of hydroxyapatite for bone tissue engineering. Acta Biomater 2005; $1: 545-52$.

[23] Gao Z, Chen F, Zhang J, et al. Vitalisation of tubular coral scaffolds with cell sheets for regeneration of long bones: a preliminary study in nude mice. Br J Oral Maxillofac Surg 2009; $47: 116-22$

(C) Shigematsu et al.; Licensee Bentham Open.

This is an open access article licensed under the terms of the Creative Commons Attribution Non-Commercial License (http://creativecommons.org/ licenses/by-nc/3.0/), which permits unrestricted, non-commercial use, distribution and reproduction in any medium, provided the work is properly cited. 